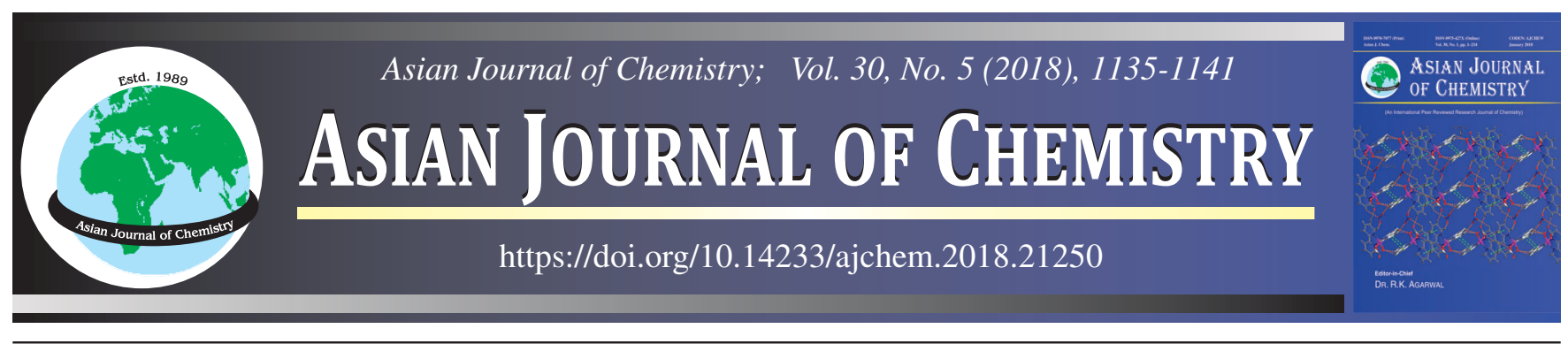

\title{
Effect of Clay Modification and Preparation Method on Crystalline Structure of Isotactic Polypropylene/Organoclay Nanocomposites
}

\author{
Murefah M. Anazy ${ }^{1, *}$, Wafa K. Mekhamer ${ }^{2}$ and Layla A. Al-Juhaiman ${ }^{2}$
}

${ }^{1}$ Department of Chemistry, Princess Nora Bint Abdul Rahman University, Riyadh, Saudi Arabia

${ }^{2}$ Department of Chemistry, King Saud University, Riyadh, Saudi Arabia

*Corresponding author: E-mail: taazdoodee@ hotmail.com

Received: 24 January 2018;

Accepted: 7 February 2018;

Published online: 29 March 2018;

AJC-18855

Isotactic polypropylene (PP)/organoclay (OC) nanocomposites was prepared in two different ways, specifically melt and solution. Getting organoclay, cationic surfactant, cetylpyridinium chloride (CPC) may use to modify Khulays clay (Saudi Arabia) once covering by Na ions. To establish correspondence between the preparation method and the degree of intercalation/exfoliation of organoclay in polypropylene matrix, Fourier transform infrared (FTIR), X-ray diffraction (XRD), transmission electron microscopy (TEM) and scanning electron microscopy (SEM) screening were performed. The result revealed that the prepared PP/OC nanocomposites by melt method have the most extensive dispersion of organoclay particles and the highest level of exfoliation comparing to that prepared by solution method. Also the crystallinity $\left(\mathrm{X}_{\mathrm{C}}\right)$ degree of PP/OC nanocomposites at dissimilar organoclay content $(1,5$ and 10 wt. \%) was calculated regarding $\mathrm{XRD}$ result. All nanocomposites $\mathrm{X}_{\mathrm{C}}$ was higher than that of neat polypropylene. In addition, crystalline structure of PP/OC nanocomposites which prepared by solution method showed absolutely dissimilar comparing to those prepared by melting method.

Keywords: Polypropylene, Organoclay, Nanocomposites.

\section{INTRODUCTION}

During the past decade, the use of organically modified clays for nanocomposite clay polymer attracted great attention, whether material science and technology [1-3], physical mixture of raw hydrophilic clay and other silicate layer. Due to variations in chemical affinity between clay and hydrophobic polymer, clay may not form a nancomposite. Moreover, the clay stacks platelets are held strongly together by electrostatic forces. For these reasons, the clay must be modify in chemical structure before using to make polymer/clay nanocomposite. To modify clay surface easily, traditional ion exchange method is the appropriate. Because the cations are not strongly bound to clay surface, so small cations such as $\mathrm{Na}^{+}, \mathrm{Ca}^{2+}, \mathrm{K}^{+}$, etc. can replace present cations on the clay. By exchanging ions present in between clay layers with various organic cations, clay can be computable with a wide variety of matrix polymers. Simultaneously, this process services to detach the clay platelets, resulting in they may be more easily intercalated and exfoliated. By exchanging of sodium cations on clay surface for organic cations in what is known surfactants, the surface energy of clay decreases and the interlayer spacing expands. The resulting modified clay is termed organoclay. The exfoliation degree of organoclays depends on the surfactant chemical structure, cation exchange degree and silicate layer thickness [4]. Organically modified clay has been widely studied fundamentally and in practical applications in the area of organic-inorganic hybrids, composites and nanoscale composites [5]. Such clay facilitates modifications used of proper organic modifier that can control the final structure and nanocomposites end properties, especially flammability reduction of polymers and for other applications likewise.

Contrary, in situ polymerization, nanocomposites can be prepared by a combination of melt or/and solution compounding. It is most economically attractive and environmentally viable since does not require any solvent and it is executable using scalable melt extrusion. Despite the dispersion being particularly difficult related to the polymer high viscosity and nanoparticles low bulk density, which makes feeding into extruders very difficult. The low viscosity of solution blending that allows the particle dispersion [6].

Polymer-clay nanocomposites preparation depends upon several factors such as nature of polymer, preparation method, clay nature and organic modifier. Commercially available organoclays usually incorporate short aliphatic chains and benzyl groups using ammonium surfactants [7-9]. The limited availability of commercial organoclays modified with ammonium ions; which are either mostly aliphatic in nature or having 
very few types of polar organics; main catalyst for preparation of in-house modified clays provides internal adjustment using surfactants.

One of the most important commodity polymers is polypropylene (PP). It is widely used for packaging, textiles and automobile with furniture components, because of its good process ability, excellent recyclability, low density (0.90-0.91 $\mathrm{g} / \mathrm{cm}^{3}$ for a typical commercial grade), water and chemical highly resistance, good thermal aging stability, good toughness and low cost [7]. Present work focused on the role of the preparation method on the properties of modified organic clay impregnation in non-polar polymer matrices such as isotactic polybutylene. To achieve this purpose, a natural clay from Khulays region in Saudi Arabia was modified in our lab using one type cationic surfactant, cetylpyridinium chloride (CPC). In addition isotactic polypropylene/organoclay nanocomposites were prepared at different organoclay content (1, 5 and 10 wt. \%) by two different methods, namely melt compounding and solution mixing. The prepared PP/OC nanocomposites were investigated using Fourier transform infrared spectroscopy (FTIR), X-ray diffraction (XRD), scanning electron microscopy (SEM) and transmission electron microscopy (TEM).

\section{EXPERIMENTAL}

A commercially isotactic polypropylene (PP) was used as a matrix. Polypropylene was supplied by Saudi Basic Industries Corporation (SABIC). Polypropylene 115 is the trade name of polypropylene with Average Mw $281155.5 \mathrm{~g} / \mathrm{mol}$, a melting temperature of $171^{\circ} \mathrm{C}$. The melt flow index (MFI) equal to 25 $\mathrm{g} / 10 \mathrm{~min}$ (measured at $230{ }^{\circ} \mathrm{C}$ under $2.16 \mathrm{Kg}$ load) and a density of $905 \mathrm{~kg} / \mathrm{m}^{3}$ (measured at $23{ }^{\circ} \mathrm{C}$ ).

Clay was collected locally from Khulays section, north of Jeddah in Saudi Arabia and grindedin quartz mortar until the particle size was less than $60 \mu \mathrm{m}$. Quantitative XRD of clay sample has realized in previous work [10]. The clay sample from Khulays section consist mainly of montmorillonite (35.22 $\%)$, kaolinite $(13.33 \%)$, mica $(22.8 \%)$, quartz $(8.57 \%)$, feldapars $(6.66 \%)$ and ilmenite $(5.714 \%)$ that had indicated XRD results. Remaining components were dolomite $(3.81 \%)$ and gypsum, calcite $(3.81 \%)$. The cetylpyridinium chloride (CPC) is a cationic surfactant, has molecular formula $\mathrm{C}_{21} \mathrm{H}_{38} \mathrm{Cl}$, with a molecular weight of $339.99 \mathrm{~g} \mathrm{~mol}^{-1}$ and a purity of 99 $\%$, which provided by $\mathrm{BDH} \& \mathrm{Co}$, Xylene, $\mathrm{C}_{6} \mathrm{H}_{5} \mathrm{CH}_{3}$, has a molecular weight of $92.14 \mathrm{~g} / \mathrm{mol}$ and a purity of $99.5 \%(\mathrm{BDH}$ \& $\mathrm{Co}$ ) and $58.44 \mathrm{~g} / \mathrm{mol} \mathrm{NaCl}$, molecular weight.

Clay washing and saturation with sodium ion: In $2 \mathrm{~L}$ of distilled water, $100 \mathrm{~g}$ of local clay were dispersed and shaked for $2 \mathrm{~h}$ then left overnight. The supernatant solution was decanted. These procedures were repeated three times. Then the washed clay was transferred into $500 \mathrm{~mL}$ of $0.5 \mathrm{M} \mathrm{NaCl}$ solution and the suspension was further shaked for $2 \mathrm{~h}$ and also left overnight. This process was repeated three times. In order to eliminate the leftover salt. Na-saturated clay was washed with distilled water and separated by centrifuging until the $\mathrm{AgNO}_{3}$ test for chloride ion was negative. The saturated clay with sodium cation (Na-clay) was dried at $120{ }^{\circ} \mathrm{C}$ and finally mashed in a mortar and stored in a desiccator over $\mathrm{CaCl}_{2} .5 \mathrm{~g}$ of resulted Na-clay ( $80 \mathrm{meq} / 100 \mathrm{~g}$ ) were dispersed for $24 \mathrm{~h}$ at room tempe-rature in $500 \mathrm{~mL}$ d. water, using a magnetic stirrer. Aqueous solution of (cetylpyridinium chloride) was prepared by dissolution of $1.44 \mathrm{~g}$ of cetylpyridinium chloride in $100 \mathrm{~mL}$ of distilled water. (The concentration of cetylpyridinium chloride solution is equivalent to one time of CEC of clay sample). Cetylpyridinium chloride solution gradually added under magnetic stirring to the dispersion of $\mathrm{Na}$-clay for $12 \mathrm{~h}$ with continuous stirring. The cation exchange reaction occurs rapidly. The exchanged clay was filtered and washed with distilled water until no chloride ion was detected with $0.1 \mathrm{~N} \mathrm{AgNO}_{3}$ solutions. The resulting organoclay (OC) was dried at $60^{\circ} \mathrm{C}$ for $24 \mathrm{~h}$.

Finally, fine powder of organoclay has obtained, using a mortar and pestle to powder the resultant material.

Preparation of organoclay and polymer nanocomposites: Present study involved the composites which fabricated by melt blending of polypropylene containing $0,1,5$ and $10 \mathrm{wt}$ $\%$ organoclay using a Laboratory Mixing Extruder (LME, Dynisco, USA). The LME is a lab-scale continuous blending apparatus with barrel diameter and rotor diameter approximately $19 \mathrm{~mm}$ and $18.8 \mathrm{~mm}$, respectively. The nanocomposites was fabricated by two steps. First, both neat polypropylene and clay were manually mixed together. Afterward, the mix was melt blended using the LME at a constant barrel temperature of $230{ }^{\circ} \mathrm{C}$, die temperature of $235^{\circ} \mathrm{C}$ and rotor speed of $200 \mathrm{rpm}$. In the second step, these pellets were extruded into ribbons. The ribbons thickness was $0.30 \pm 0.05 \mathrm{~mm}$ and their width was $7.5 \pm 1.5 \mathrm{~mm}$. These ribbons were used for further analysis.

Isotactic polypropylene and PP/OC nanocomposite films were prepared by a solution method at different wt $\%$ of organoclay $(0,1,3,5$ and $10 \mathrm{wt} \%) .2 \mathrm{~g}$ of polypropylene was dissolved in $10 \mathrm{~mL}$ of xylene in a flask equipped at $140{ }^{\circ} \mathrm{C}$ under reflux. The mixture was stirred until complete polymer dissolution. Appropriate mass of organoclay was dispersed in polypropylene solution with stirring and gentle heating for $2 \mathrm{~h}$, then the solution has been poured into petri dishes with the size of $100 \times 20 \mathrm{~mm}$ allowing the xylene to evaporate at room temperature. The film removed late from the glass plate after $72 \mathrm{~h}$ at room temperature. Preparation of PP/OC nanocomposite is illustrated in the Scheme-I.

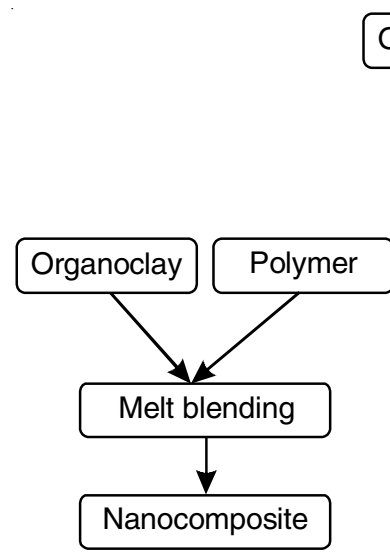

(a)

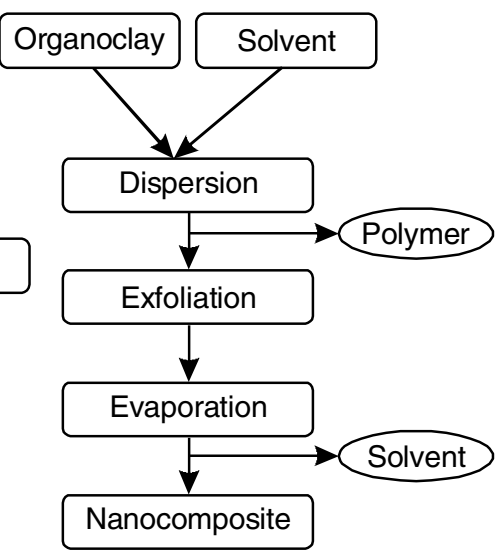

(b)
Scheme-I: Preparation of PP/OC nanocomposites using (a) melt method (b) solution method 
A summary of the polypropylene sample code which prepared by melt and solution methods at different wt $\%$ of organoclay were shown in Table-1.

Characterization PP/OC nanocomposites: Na-clay structures and organoclay and prepared $\mathrm{PP} / \mathrm{OC}$ nanocomposite films were investigated using Fourier-transform infrared (FTIR) in the range $4000-400 \mathrm{~cm}^{-1}$ using FTIR Perkin Elmer Spectrscopy 1000 , to characterize nanocomposites.

Intercalation level evaluation of organoclay was performed using a PanlyticalX' pert Pro X-ray diffractometer, dispersion of organoclay in polypropylene matrix and crystallinity of PP/ OC nanocomposites. The diffraction patterns were scanned at room temperature at both small angles $(2 \theta=3-50)$. The $\mathrm{X}$-ray beam $\mathrm{Cu} \mathrm{K}$ radiation $(\lambda=1.54056 \AA)$ operated at $40 \mathrm{kV}$ and $40 \mathrm{~mA}$.

Microstructures of polymer/organoclay nanocomposites was examined by TEM. Ultrathin sections $70-100 \mathrm{~nm}$ in thickness has been cut with a diamond knife using a JEOL JSM6060 LV Transmission Electron Microscopy. TEM was operated at an accelerating voltage of $100 \mathrm{KV}$. While SEM using a JEOL JSM-6360LV scanning electron microscope (SEM) investigated the morphologies of polymer and PP/OC nanocomposites. The fracture surfaces of the samples were coated with thin layers of gold of about $10 \AA$ and then the fractured surface was examined by SEM at $20 \mathrm{KV}$ and different magnifications.

\section{RESULTS AND DISCUSSION}

FTIR: FTIR is a method to probe the molecular environment of organic cation within the organoclay [11]. Fig. 1a shows the FTIR spectra of Na-clay, cetylpyridinium chloride and organoclay. The absorption band at $3624.5 \mathrm{~cm}^{-1}$ was present due to hydroxyl stretching vibration of structural water within the Na-clay interlayer. The broad band at 3447 and $1637 \mathrm{~cm}^{-1}$ were present due to that stretching vibrations for hydroxyl group of the interlayer water and to the absorption band of $-\mathrm{OH}$ bending respectively. Stretching vibration band of $\mathrm{Si}-\mathrm{O}$ was presented at $1032.61 \mathrm{~cm}^{-1}$, while the bands at near 527.75 and $466.58 \mathrm{~cm}^{-1}$ were attributed to $\mathrm{Al}-\mathrm{O}-\mathrm{Si}$ and $\mathrm{Si}-\mathrm{O}-\mathrm{Si}$ bending vibration, respectively $[12,13]$.

Both strong peaks at 2915 and $2849 \mathrm{~cm}^{-1}$ showed with FTIR spectrum of cetylpyridinium chloride sample can be assigned to the asymmetric and symmetric stretching vibrations of the $\mathrm{C}-\mathrm{H}$ in the alkyl chains of the cetylpyridinium chloride molecules, respectively [14]. The organoclay spectrum showed a new characteristic peak which appears at 2926.62 and $2853.28 \mathrm{~cm}^{-1}$ corresponding to the $-\mathrm{CH}_{2}$ asymmetric and
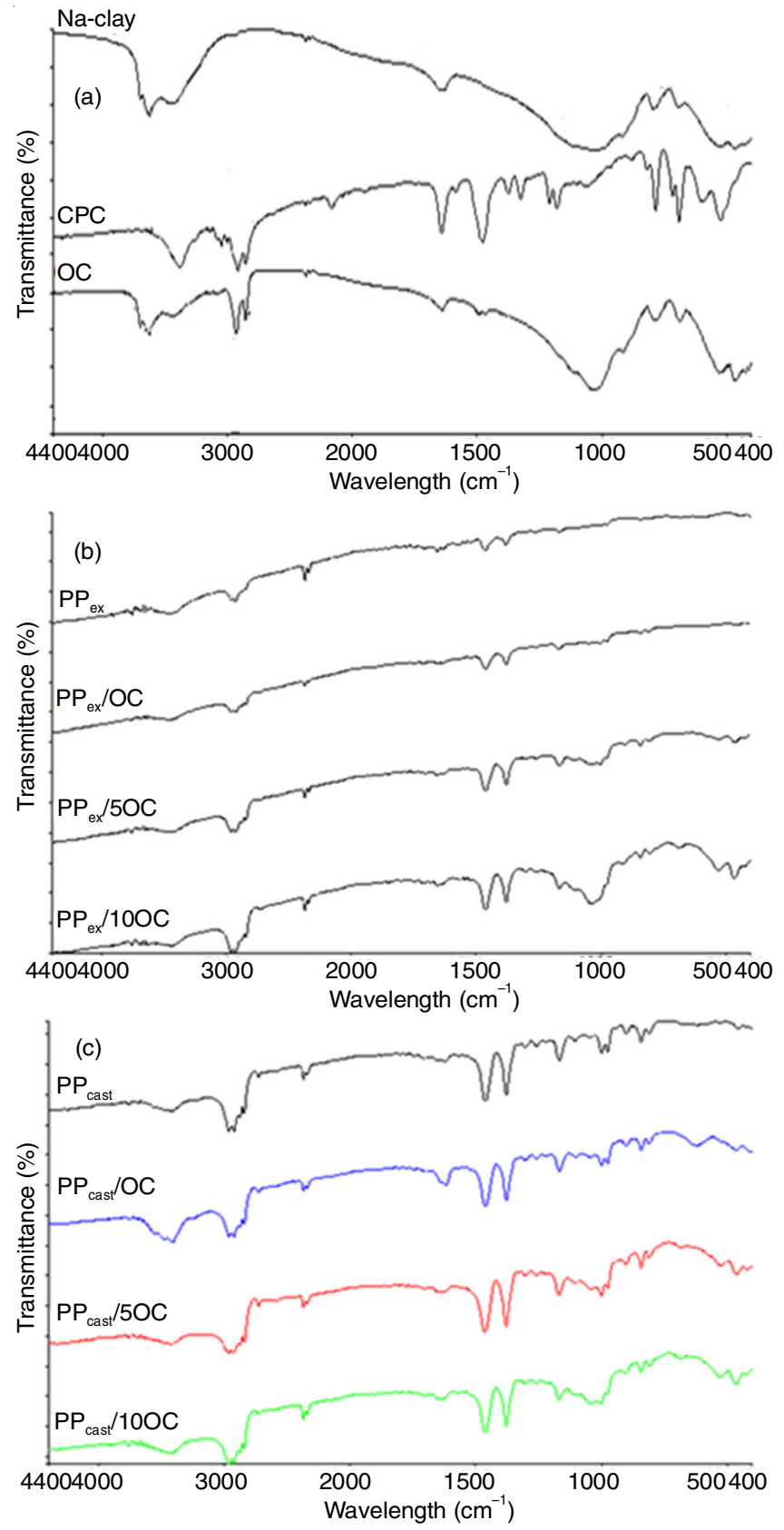

Fig. 1. FTIR spectra of Na-clay, cetylpyridinium chloride, organoclay (a), $\mathrm{PP}_{\mathrm{ex}}, \mathrm{PP}_{\mathrm{ex}} / \mathrm{OC}(\mathrm{b})$ and $\mathrm{PP}_{\text {cast }}, \mathrm{PP}_{\text {cast }} / \mathrm{OC}$ nanocomposites (c)

$-\mathrm{CH}_{2}$ symmetric stretching vibrations respectively. Moreover the stretching band of the Al-OH groups at $3624.5 \mathrm{~cm}^{-1}$ for Na-clay was shifted to $3625.30 \mathrm{~cm}^{-1}$ in organoclay spectrum. Similarly, the bending hydration mode in water (adsorbed

TABLE-1

SAMPLE CODE OF POLYPROPYLENE PREPARED BY MELT AND SOLUTION METHODS AT DIFFERENT WT \% OF ORGANOCLAY

\begin{tabular}{ll}
\hline \multicolumn{1}{c}{ Sample code } & \multicolumn{1}{c}{ Samples } \\
\hline $\mathrm{PP}_{\mathrm{ex}}$ & Isotactic polypropylene prepared by melt method (extrudate) \\
$\mathrm{PP}_{\mathrm{ex}} / 1$ organoclay & $\mathrm{PP} /$ clay nanocomposites prepared by melt method in presence of $1 \%$ organoclay \\
$\mathrm{PP}_{\mathrm{ex}} / 5$ organoclay & $\mathrm{PP} /$ clay nanocomposites prepared by melt method in presence of $5 \%$ organoclay \\
$\mathrm{PP}_{\mathrm{ex}} / 10$ organoclay & $\mathrm{PP} /$ clay nanocomposites prepared by melt method in presence of $10 \%$ organoclay \\
$\mathrm{PP}_{\text {cast }}$ & Isotactic polypropylene prepared by solution method (casting) \\
$\mathrm{PP}_{\text {cass }} / 1$ organoclay & $\mathrm{PP} /$ clay nanocomposites prepared by solution method in presence of $1 \%$ organoclay \\
$\mathrm{PP}_{\text {cast }} / 5$ organoclay & $\mathrm{PP} /$ clay nanocomposites prepared by solution method in presence of $5 \%$ organoclay \\
$\mathrm{PP}_{\text {cast }} / 10$ organoclay & $\mathrm{PP} /$ clay nanocomposites prepared by solution method in presence of $10 \%$ organoclay \\
\hline
\end{tabular}


water) of the - $\mathrm{OH}$ groups are characterized by a broad band at $1637 \mathrm{~cm}^{-1}$. This band shifted to $1639 \mathrm{~cm}^{-1}$ in the FTIR spectrum of the organoclay sample, indicating intercalation of cetylpyridyium chloride molecules between the silica layers in Naclay. The broad band detected at $3447.95 \mathrm{~cm}^{-1}$ is due to $-\mathrm{OH}$ stretching band for interlayer water. This band shifted to $3446.15 \mathrm{~cm}^{-1}$ in spectrum of organoclay. All of these shifts refer to the organophilic modification of the Na-Clay by cetylpyridinium chloride.

The interaction between organoclay and polypropylene was proved by FTIR. The spectra of polypropylene, $\mathrm{PP}_{\mathrm{ex}} / \mathrm{OC}$ and $\mathrm{PP}_{\text {cast }} / \mathrm{OC}$ nanocomposites at different organoclay contents $(1,5$ and $10 \mathrm{wt} \%)$ were shown in Fig. 2b and 2c. The absorption bands at 1460 and $1375 \mathrm{~cm}^{-1}$ azre $\mathrm{C}-\mathrm{H}$ bending vibration of polypropylene. The broad peak around $3000 \mathrm{~cm}^{-1}$ due to $\mathrm{C}-\mathrm{H}$ symmetrical stretching and anamorphic vibration. Absorption bands at $1300-800 \mathrm{~cm}^{-1}$ range were distinguished of the stretching and bending vibrations of polypropylene hydrocarbon structure. The observed bands shape of polypropylene between $1150-830 \mathrm{~cm}^{-1}$ for both $\mathrm{PP}_{\mathrm{ex}} / \mathrm{OC}$ and $\mathrm{PP}_{\text {cast }} /$ OC nanocomposites corresponding to the interaction between organoclay and polypropylene. This result revealed that the PP/OC nanocomposites were successfully formed.

X-ray diffraction (XRD): X-ray diffraction consider the main method in this study. Interlayer spacing can be calculated from X-ray diffraction data. Fig. 2a shows the XRD patterns of Na-clay, cetylpyridinium chloride and organoclay. After the reaction of ion exchange of Na-clay with cetylpyridinium chloride, the interlayer spacing increased from $13.9 \AA$ for Na-clay to $29.9 \AA$ for organoclay indicating that the cetylpyridinium chloride was successfully intercalated between the interlayer spacing of Na-clay. Cetylpyridinium chloride might take on a bilayer structure parallel to adjacent silicate layers in the interlayer spacing [15] compared with those traditional organo-montmorillonites modified using cation surfactants [16-18]. Even at lower concentration, cetylpyridinium chloride may shows the maximum interlayer spacing, e.g., 1 time CEC of clay, which is very important in preparing low cost organoclay for industrial applications. Moreover, XRD was also applied to analyze the structure characteristics of polypropylene and $\mathrm{PP} / \mathrm{OC}$ nanocomposites prepared by melting and casting method. Fig. $2 \mathrm{~b}$ and $2 \mathrm{c}$ show XRD patterns of $\mathrm{PP}_{\mathrm{ex}} / \mathrm{OC}$ and $\mathrm{PP}_{\text {cast }} / \mathrm{OC}$ nanocomposites at different wt $\%$ of organoclay. The characteristic organoclay peaks disappeared in both PP/OC nanocomposites prepared either by melting or solution methods, while the sharp peaks of pure polypropylene are observed near its original position. The disappearance of the main investigated clay peaks (Fig. $2 \mathrm{~b}$ and $2 \mathrm{c}$ ) indicates that the average organoclay interlayer spacing in PP/OC nanocomposite is larger than $5.8 \mathrm{~nm}$ according to Bragg equation and could be a sign that a possible organoclay exfoliation in the polypropylene matrix has occurred. This may be a result of strong interaction between silicate layer of organoclay and polymer molecule [19]. Fig. $2 \mathrm{~b}$ and $2 \mathrm{c}$ clarify that the diffrac-tion peaks at $25=13.9,16.8$, 18.4 and 21.8 corresponded to the planes (110), (040), (130) and (111) of 5-phase crystallite of polypropylene, respectively. The 5-phase crystallite was still the main crystallite form of polypropylene in PP/OC nanocomposites. 5-Phase diffraction
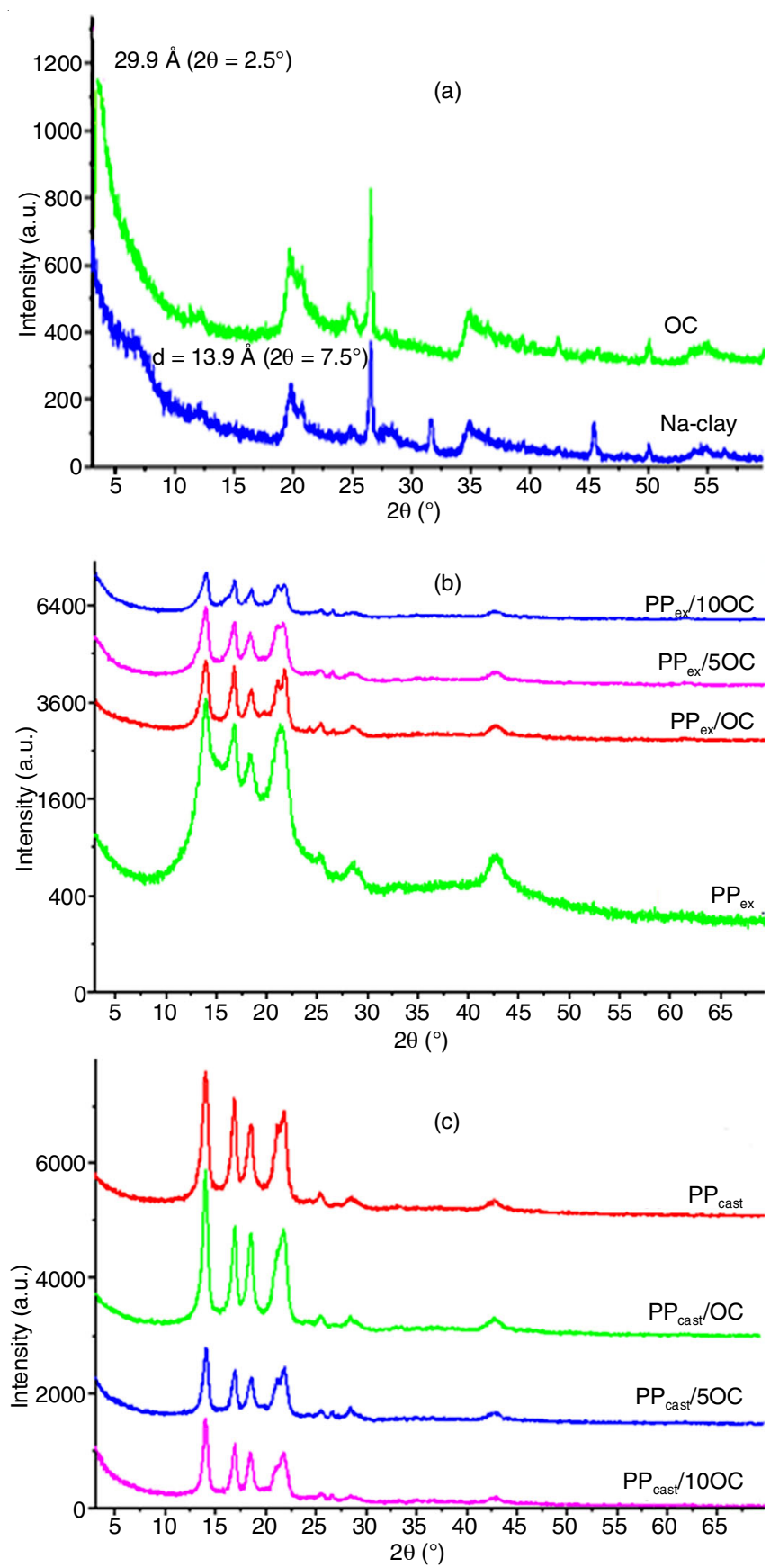

Fig. 2. $\mathrm{XRD}$ of Na-clay, organoclay (a), $\mathrm{PP}_{\mathrm{ex}} / \mathrm{OC}$ nanocomposites (b) and $\mathrm{PP}_{\text {cast }} / \mathrm{OC}$ nanocomposites (c)

peaks and 5-phase crystallite were not showed in XRD. This conclusion agreed with former works [20] and the phase of dominate crystal did not changed resulting in that alteration of clay existence.

Fig. 3 shows the crystallinity percentage of $\mathrm{PP}_{\mathrm{ex}} / \mathrm{OC}$ and $\mathrm{PP}_{\text {cast }} / \mathrm{OC}$ nanocomposites respectively. The percentage of crystallinity $\left(\mathrm{X}_{\mathrm{C}}\right)$ of polypropylene was calculated from XRD pattern using the Scherer's equation (eqn. 1).

$$
X_{C}=\left(\frac{I_{c}}{I_{a}+I_{c}}\right) \times 100
$$

where $I_{a}$ and $I_{c}$ are the integrated intensity of the amorphous and crystalline phases respectively. 


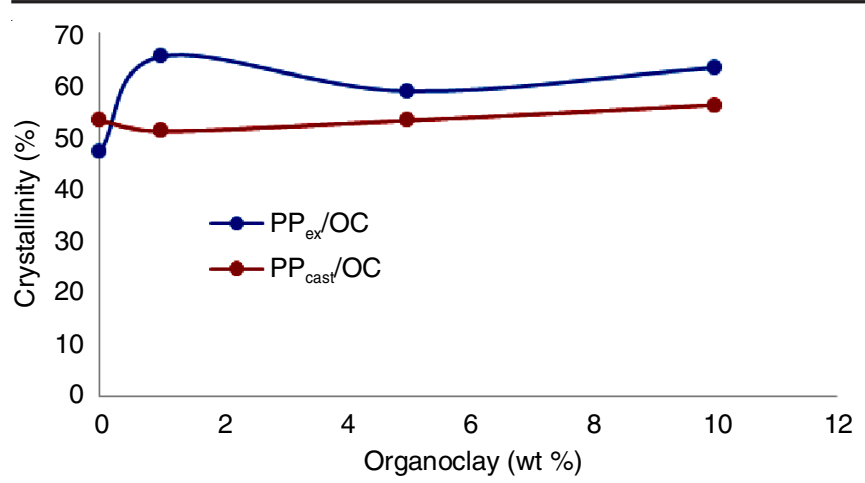

Fig. 3. Percentage of crystallinity $\left(\mathrm{X}_{\mathrm{C}}\right)$ of polypropylene at different wt $\%$ of organoclay for both $\mathrm{PP}_{\mathrm{ex}} / \mathrm{OC}$ and $\mathrm{PP}_{\text {cas }} / \mathrm{OC}$ nanocomposites

It was stated that the percentage of crystallinity $\left(\mathrm{X}_{\mathrm{C}}\right)$ of all $\mathrm{PP}_{\mathrm{ex}} / \mathrm{OC}$ nanocomposites is higher than that of neat polypropylene. This increase can be attributed to the dispersed organoclay layer in polypropylene matrix, which enhances the crystallization process of polypropylene by acting as "nucleating agent" [21,22]. The percentage of crystallinity $\left(\mathrm{X}_{\mathrm{C}}\right)$ of $\mathrm{PP}_{\mathrm{ex}} / \mathrm{OC}$ nanocomposites increased with increasing loading content of organoclay and it is also clear that the maximum $X_{C}$ is reached at $1 \mathrm{wt} \%$ of organoclay (Fig. 3). Thereafter, increasing the organoclay loading resulted in a gradual decrease of $\mathrm{X}_{\mathrm{C}}$. This conduct was recognized to limit the polypropylene chain segments mobility. This limitation increases with wt \% of organoclay in polypropylene matrix increasing, which results in less perfect crystals $[23,24]$. Additionally, there are two conflicting effects of organoclay on that crystallization process, i.e. nucleating effect and growth retardation. Both were affected by loading and dispersion state of organoclay [25]. An extreme amount of nucleation sites and retarded crystal growth lead to production of fine crystals and consequently yield crystallinity degree low [26]. Similar case was also observed by Xie et al. [27] and Chafidz et al. [28], where the maximum value of $\mathrm{Xc}$ was reached at low clay content and decreased with nanoclay content increasing.

Conversely, crystallinity $\left(\mathrm{X}_{\mathrm{C}}\right)$ percentage of $\mathrm{PP}_{\text {cas }} / \mathrm{OC}$ nanocomposites was slightly affected by the presence of organoclay comparing to $\mathrm{PP}_{\mathrm{ex}} / \mathrm{OC}$ nanocomposites (Fig. 3). This variation may be attributed to poor dispersion of organoclay in polypropylene matrix as aresult of aggregation of organoclay particles rather than $\mathrm{PP}-\mathrm{OC}$ interaction at the interface which occur due to the processing conditions. It can be conclude that the good dispersion and intercalation of organoclay for $\mathrm{PP}_{\mathrm{ex}} / \mathrm{OC}$ enhances the crystallization process of polypropylene by acting as "nucleating agent".

Electron microscopy: In order to envisage organoclay particles dispersion into polypropylene matrix and to favour the interpretation of XRD patterns, transmission electron microscopy and scanning electron microscopy have been investigated to the organoclay dispersion and interfacial features in nanocomposites.

Fig. $4 \mathrm{a}$ and $4 \mathrm{~b}$ shows $\mathrm{PP}_{\mathrm{ex}} / 10$ organoclay and $\mathrm{PP}_{\text {cast }} / 10$ organoclay TEM micrographs. The organoclay particles represented by dark areas while grey ones refers to the continuous polypropylene matrix. $\mathrm{PP}_{\mathrm{ex}} / \mathrm{OC}$ nanocomposites image showed exfoliated single clay layers (red rows), while the images of $\mathrm{PP}_{\text {cass }} / \mathrm{OC}$ nanocomposites showed some clay is present as exfoliated layers (red rows) and most of the clay is present in aggregated particles (blue rows).

$\mathrm{PP}_{\text {ex }} / 10$ organoclay nanocomposites are highly exfoliated compared to $\mathrm{PP}_{\text {cast }} / 10$ organoclay that showed by TEM image. This result qualified to that clay sheets, which were predominantly delaminated in the xylene dispersion, tend to aggregate back into stacks during solvent evaporation. This is a welldocumented in literature as the secondary aggregation which occurs due to the processing conditions. Such phenomenon
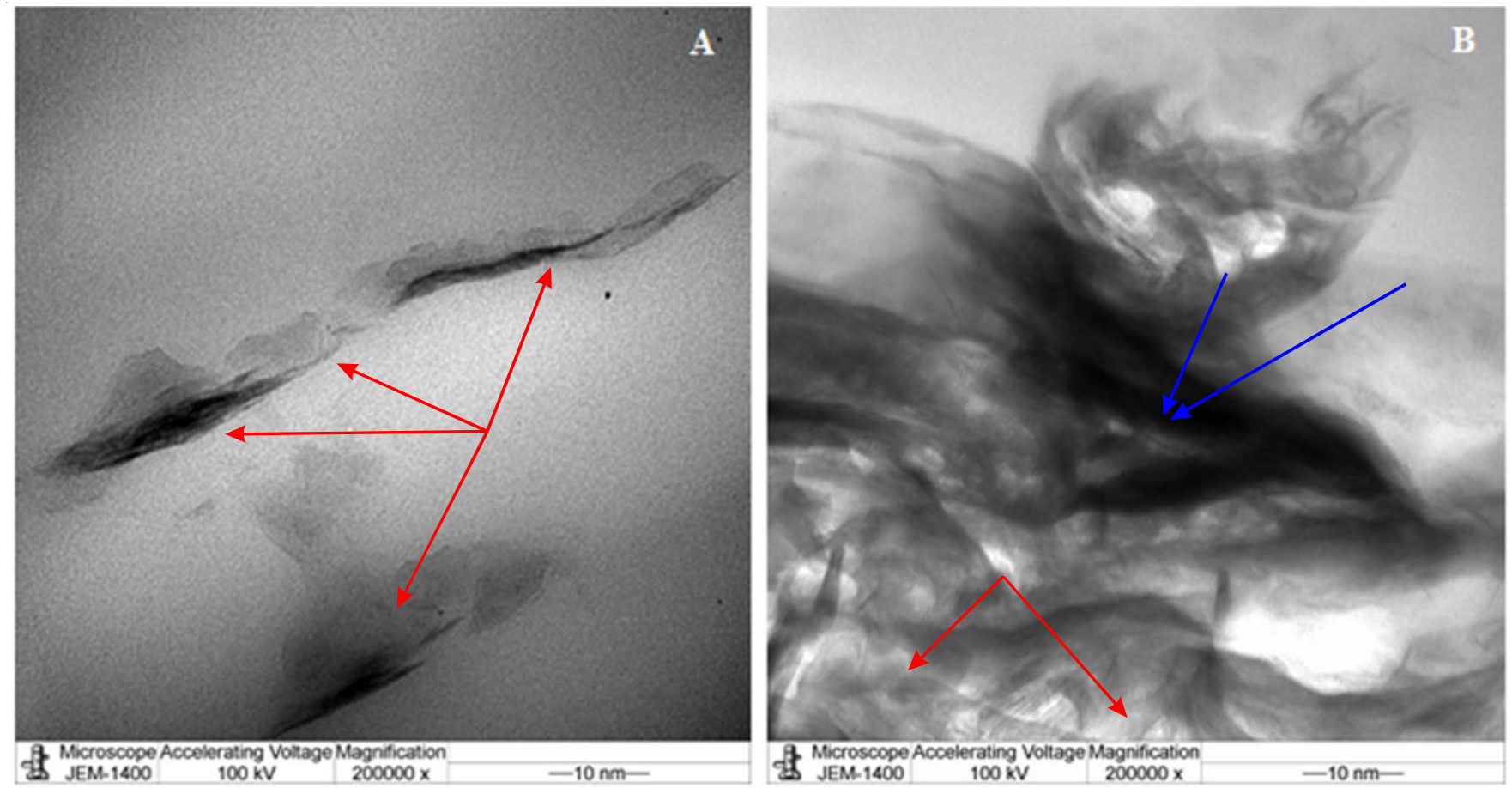

Fig. 4. TEM images of (a) $\mathrm{PP}_{\mathrm{ex}} / 10$ organoclay nanocomposites and (b) $\mathrm{PP}_{\text {cast }} / 10$ organoclay nanocomposites 
takes place along with the expulsion of the polymer chains, so that the intercalated silicate stacks are formed (blue rows, Fig. 4b).

SEM was implemented on neat polypropylene and PP/ $\mathrm{OC}$ nanocomposites in order to investigate the organoclay dispersion of PP/OC nanocomposites. Fig. 5a-f displays representation micrographs of polypropylene, $\mathrm{PP} / 1$ organoclay and PP/10 organoclay nanocomposites prepared by two different methods. Using melting method the polypropylene has been prepared a continuous crystalline lamellar stakes of different sizes (white colour) which are embedded in amorphous part (dark colour, Fig. 5a). The microstructure of the $\mathrm{PP}_{\mathrm{ex}} / \mathrm{OC}$ nanocomposites is substantially changed after incorporation of organoclay into polypropylene matrix. The organoclay particles were not visible for PP/OC nanocomposites indicating better homogenous dispersion of silicate layers in the polypropylene matrix (Fig. 5b-c). It is difficult to estimate the size of the stacks because the stacks are nonisometric and randomly dispersed in polypropylene matrix. However the size of the stacks in $\mathrm{PP}_{\mathrm{ex}} / 1$ organoclay are very small (marked by circle (a) in Fig. 5b compared to larger crystalline lamellar stacks with $\mathrm{PP}_{\mathrm{ex}} / 10$ organoclay nanocomposite (marked by circle $\mathrm{B}$ in Fig. 5c). The polymer chains intercalation and the wetting capability of the polymer matrix are enhanced with increasing organoclay content in the polypropylene matrix which leads to a significant increase of crystalline lamellar sizes compared to neat polypropylene morphology.

The crystalline structure of neat or $\mathrm{PP}_{\text {cast }} / \mathrm{OC}$ nanocomposites showed totally different crystalline structure compared with those prepared by melting method (Fig. 5d). The crystalline structure of neat polypropylene forms has aggregate and irregular spherulites (white colour, Fig. 5d), which is impeded in amorphous phase (dark colour). Assimilation of low loadings of organoclay (e.g., $1 \%$ ) in polypropylene matrix, alters the size and shape of these spherulites (Fig. 5e). The spherulites grew impinged on each other and formed particular polygonal spherulites, showed less perfection and the sharp spherulite boundaries became more diffuse. A biggest spherulites with clear boundaries was obtained at high loading of organoclay in polypropylene matrix ( $\mathrm{PP}_{\text {cast }} / 10$ organoclay). This influence can be explained by nucleation effect of organoclay resulting in crystallization and hence formation of larger spherulites (Fig. 5f). That crystalline lamellar stakes of polypropylene in $\mathrm{PP} / \mathrm{OC}$ nanocomposites prepared with melting is in agreement with crystallization studies on polypropylene and other polymers $[15,24,26]$, while, the presence of the spherulites structure in polypropylene or PP/OC nanocomposites prepared with solution was not stated.
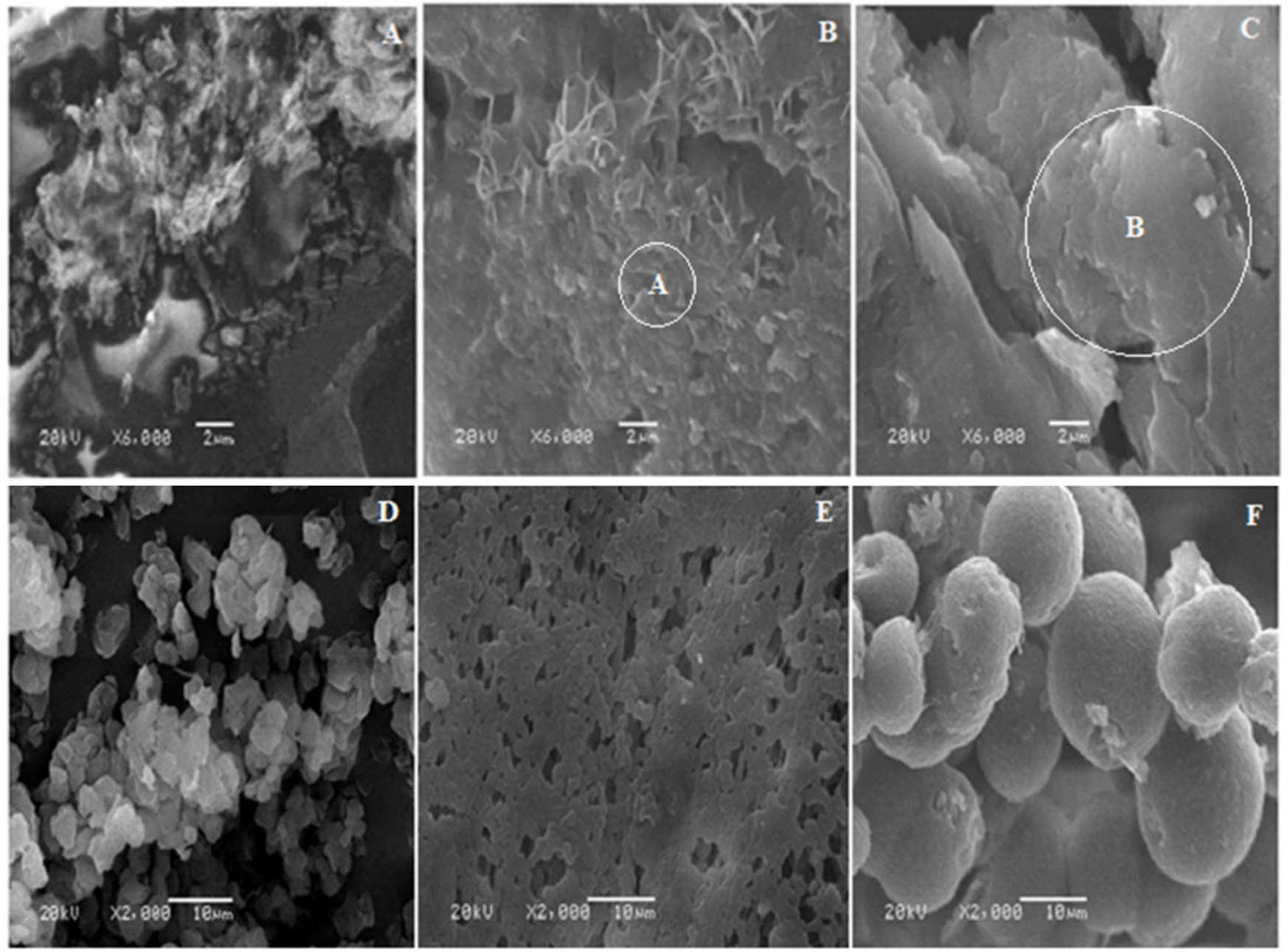

Fig. 5. SEM of $\mathrm{PP}_{\mathrm{ex}}(\mathrm{a}), \mathrm{PP}_{\mathrm{ex}} / 1$ organoclay (b), $\mathrm{PP}_{\mathrm{ex}} / 10$ organoclay (c), $\mathrm{PP}_{\text {cast }}(\mathrm{d}), \mathrm{PP}_{\text {cast }} / 1$ organoclay (e) and $\mathrm{PP}_{\text {cast }} / 10$ organoclay (f) nanocomposites 
The SEM and TEM analysis revealed that the preparation procedures have a marked influence on the $\mathrm{PP} / \mathrm{OC}$ nanocomposites morphology. The nanocomposites prepared in the melt under shear were found to possess the most extensive dispersion of nanometric clay particles and the highest level of exfoliation, at least for organoclay loadings up to about 10 wt $\%$.

\section{Conclusion}

Clay modification with cationic surfactant accomplished ameliorate silicate layers dispersion in the polypropylene matrix. SEM and TEM confirmed that preparation method has a marked influence on the crystallization behaviour and morphology of PP/OC composites. Poorly dispersed presence of clay particles was revealed incomposites prepared from solution, whereas the nanocomposites prepared by melt method were found to posses the most extensive dispersion of nanometric clay particles and high levels of exfoliation.

\section{ACKNOWLEDGEMENTS}

This research project was supported by a grant from the Research Center of the Female Scientific and Medical Colleges, Deanship of Scientific Research, King Saud University, Kingdom of Saudi Arabia.

\section{REFERENCES}

1. M. Aydin, T. Uyar, M.A. Tasdelen and Y. Yagci, J. Polym. Sci. A Polym. Chem., 53, 650 (2015);

https://doi.org/10.1002/pola.27487.

2. J.J. Decker, K.P. Meyers, D.R. Paul, D.A. Schiraldi, A. Hiltner and S. Nazarenko, Polymer, 61, 42 (2015); https://doi.org/10.1016/j.polymer.2015.01.061.

3. H. Zou, S. Wu and J. Shen, Chem. Rev., 108, 3893 (2008); https://doi.org/10.1021/cr068035q.

4. F. Kadar, L. Szazdi, E. Fekete and B. Pukanszky, Langmuir, 22, 7848 (2006); https://doi.org/10.1021/la060144c.

5. W. H. Hoidy, M. B. Ahmad, E.A. Jaffar Al and N.A. Bt Ibrahim, Am. J. Appl. Sci., 6, 1567 (2009); https://doi.org/10.3844/ajassp.2009.1567.1572.

6. L. Minkova and S. Filippi, Polym. Test., 30, 1 (2011); https://doi.org/10.1016/j.polymertesting.2010.10.007.

7. F.C. Chiu and P.H. Chu, J. Polym. Res., 13, 73 (2006); https://doi.org/10.1007/s10965-005-9009-7.

8. S. Filippi, E. Mameli, C. Marazzato and P. Magagnini, Eur. Polym. J., 43, 1645 (2007); https://doi.org/10.1016/j.eurpolymj.2007.02.015.
9. S. Filippi, C. Marazzato, P. Magagnini, A. Famulari, P. Arosio and S.V. Meille, Eur. Polym. J., 44, 987 (2008); https://doi.org/10.1016/j.eurpolymj.2008.01.011.

10. W.K. Mekhamer, J. Saudi Chem. Soc., 14, 301 (2010); https://doi.org/10.1016/j.jscs.2010.04.013.

11. R.L. Zhu, T. Wang, J.X. Zhu, F. Ge, P. Yuan and H.P. He, Chem. Eng. J., 160, 220 (2010); https://doi.org/10.1016/j.cej.2010.03.048.

12. J.F. Xiao, Y. Hu, Q.K. Kong, L. Song, Z. Wang, Z. Chen and W. Fan, Polym. Bull., 54, 271 (2005); https://doi.org/10.1007/s00289-005-0395-0.

13. B.A. Bhanvase, D.V. Pinjari, P.R. Gogate, S.H. Sonawane and A.B. Pandit, Chem. Eng. J., 181-182, 770 (2012); https://doi.org/10.1016/j.cej.2011.11.084.

14. K. Bukka and J.D. Miller, Clays Clay Miner, 40, 92 (1992); https://doi.org/10.1346/CCMN.1992.0400110.

15. J. Zhu, Y. Qing, T. Wang, R. Zhu, J. Wei, Q. Tao, P. Yuan and H. He, J. Colloid Interface Sci., 360, 386 (2011); https://doi.org/10.1016/j.jcis.2011.04.069.

16. M. Alshabanat, A. Al-Arrash and W.K. Mekhamer, J. Nanomater., Article ID 650725 (2013); https://doi.org/10.1155/2013/650725.

17. N. Banik, S.A. Jahan, S. Mostofa, H. Kabir, N. Sharmin, M. Rahman and S. Ahmed, Bangladesh J. Sci. Ind. Res., 50, 65 (2015); https://doi.org/10.3329/bjsir.v50i1.23812.

18. Z. Xu, F. Lv, Y. Zhang and L. Fu, Chem. Eng. J., 215-216, 755 (2013); https://doi.org/10.1016/j.cej.2012.11.033.

19. L. Raka, G. Bogoeva-Gaceva, K. Lu and J. Loos, Polymer, 50, 3739 (2009); https://doi.org/10.1016/j.polymer.2009.05.044.

20. L.M. Wang, A.H. He, K. Du, Y.Q. Huang, J.Y. Dong and Z.C. Han, J. Chem. Eng. Chin. Univ., 24, 132 (2010).

21. S.K. Sharma and S.K. Nayak, Polym. Degrad. Stab., 94, 132 (2009); https://doi.org/10.1016/j.polymdegradstab.2008.09.004.

22. M. Modesti, A. Lorenzetti, D. Bon and S. Besco, Polym. Degrad. Stab., 91, 672 (2006); https://doi.org/10.1016/j.polymdegradstab.2005.05.018.

23. E. Kontou and M. Niaounakis, Polymer, 47, 1267 (2006); https://doi.org/10.1016/j.polymer.2005.12.039.

24. E. Di Maio, S. Iannace, L. Sorrentino and L. Nicolais, Polymer, 45, 8893 (2004); https://doi.org/10.1016/j.polymer.2004.10.037.

25. Q. Yuan, S. Awate and R.D.K. Misra, Eur. Polym. J., 42, 1994 (2006); https://doi.org/10.1016/j.eurpolymj.2006.03.012.

26. A. Chafidz, M.A. Ali and R. Elleithy, J. Mater. Sci., 46, 6075 (2011); https://doi.org/10.1007/s10853-011-5570-0.

27. Y. Xie, D. Yu, J. Kong, X. Fan and W.J. Qiao, Appl. Polym. Sci., 100, 4004 (2006); https://doi.org/10.1002/app.23206.

28. A. Chafidz, M. Kaavessina, S. Al-Zahrani and N.M. Al-Otaibi, J. Polym. Res., 21, 483 (2014); https://doi.org/10.1007/s10965-014-0483-7. 